\title{
ELISA METHOD FOR SERUM HEPCIDIN QUANTIFICATION IN BULGARIAN POPULATION
}

\author{
V. Manolov, B. Atanasova, V. Vasilev, K. Tzatchev and M. Velizarova \\ Department of Clinical Laboratory and Clinical Immunology, Medical Faculty, Medical University, \\ Sofia, Bulgaria
}

Summary. Hepcidin is a 25 -aminoacid cysteine-rich iron regulating peptide. Hepcidin quantification in human blood may provide further insights for the pathogenesis of disorders of iron homeostasis and might prove a valuable tool for clinicians for the differential diagnosis of anaemia. This study describes ELISA immunoassay for hepcidin quantification in human serum. We used a sandwich ELISA method from USCN Life Science inc., that consists of ready to use, pre-coated 96-well strip plate with 2 antihepcidin- 25 monoclonal antibodies. A recombinant hepcidin in 16 $\mu \mathrm{g} / \mathrm{l}$ concentration is used as a standard; it reconstitutes with $1.0 \mathrm{ml}$ standard diluent to prepare a stock solution. We correlated ELISA results of hepcidin-25 measurements in healthy population with hemodialysis patients. The sandwich ELISA was highly specific for hepcidin-25, having a low limit of quantification of $0.020 \mu \mathrm{g} / \mathrm{l}$. Hepcidin-25 concentrations were increased in hemodialysis patients (median $33.05 \mu \mathrm{g} / \mathrm{l}$, range 22.31-60.98 $\mu \mathrm{g} / \mathrm{l}, \mathrm{n}=10$ ) compared with healthy individuals (median 12.41 $\mu \mathrm{g} / \mathrm{l}$, range $6.05-18.53 \mu \mathrm{g} / \mathrm{l}, \mathrm{n}=40$ ). The use of 2 monoclonal antibodies in a sandwich ELISA format provides a robust, convenient and not very expensive method for measuring concentrations of the active form of hepcidin. It should help to improve our understanding of the role of hepcidin in regulating iron metabolism.

Key words: hepcidin, quantification, ELISA, hemodialysis, iron metabolism

\section{INTRODUCTION}

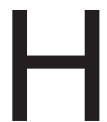

epcidin is a 25-aminoacid cysteine-rich peptide, present in human serum and urine $[11,17]$. It is synthesized predominantly by hepatocytes as an 84-aminoacid precursor protein and its mature form is released in circulation [23]. Hepcidin acts by binding to ferroportin (FPN1), the only known cell iron exporter [7], inducing its internalization and subsequent degradation in the 
cytoplasm [16]. In systemic level, hepcidin upregulation results in inhibition of iron absorption from intestinal enterocytes and iron recycling from macrophages $[9,16]$. Hepcidin expression is up-regulated by iron and inflammation and down-regulated by anaemia and hypoxia [2].

Evidence has emerged that in certain types of hereditary hemochromatosis, the cause of the disease is a deficiency of hepcidin, resulting in unregulated uptake of iron and subsequent iron overload [2, 20]. In contrast, in anemia of chronic disease and anemia of cancer, data suggest that hepcidin concentrations are increased, causing decreased absorption of iron and increased sequestration of iron in the reticuloendothelial system, which together account for the observed anemia [1, 2, $14,19,22]$. It is also suggested that patients with chronic kidney disease may have increased hepcidin, which could contribute to their observed renal anemia that is treated with erythropoietin and oral iron [4, 24].

Several methods for hepcidin quantification in human serum and urine have been reported. There are two antibody-based techniques, a dotblot assay, which has been used to measure hepcidin in urine and is considered semi-quantitative [15, 25], and a commercially available ELISA assay measuring serum prohepcidin. The diagnostic utility of the latter is controversial, since prohepcidin represents a processing intermediate rather than a biologically significant form $[12,21]$.

\section{AIM}

Our study describes a specific and non-operator demanding immunoassay for hepcidin quantification in human sera. It was designed to introduce the method into Bulgarian clinical laboratory practice as a routine method for quantification of hepcidin serum levels in the Bulgarian population, as well as to establish the reference ranges of serum hepcidin in our population.

\section{MATERIALS AND METHODS}

\section{Subjects}

This study included 40 healthy controls and 10 hemodialysis patients. The study was approved by the ethics committees of the participating institutions. Informed consent was obtained from all patients and controls and study procedures were conducted in accordance with to the Declaration of Helsinki.

40 serum samples from healthy volunteers (ages 22-60 years, mean age 33.4 years) were collected. We also obtained 10 serum samples from hemodialysis patients. After obtaining protocol approval from an institutional review board and proper informed consent, all samples were collected, stored, and deidentified to protect patient privacy. Samples were stored at $-70^{\circ} \mathrm{C}$ before analysis of hepcidin levels. Ferritin analysis was performed by using a Roche Diagnostics turbidimetric immunoassay. 


\section{ELISA procedure}

96-well microtiter plates (USCN Life Science Inc.) pre-coated with specific antibody were used. As calibrator we used hepcidin25-His diluted in standard diluent (8, $4,2,1,0.500,0.250,0.125,0.065 \mu \mathrm{g} / \mathrm{l})$. Standards or samples were then added to the appropriate microtiter plate wells with a biotin-conjugated antibody preparation specific for hepcidin. Next, avidin conjugated to horseradish peroxidase (HRP) was added to each microplate well and incubated. After TMB substrate solution was added, only those wells that contain hepcidin, biotin-conjugated antibody and enzymeconjugated avidin will exhibit a change of color. The enzyme-substrate reaction was terminated by the addition of sulphuric acid solution and the color change was measured spectrophotometrically at a wavelength of $450 \mathrm{~nm} \pm 10 \mathrm{~nm}$. The concentration of serum hepcidin in the samples was then determined by comparing the O.D. of the samples to the standard curve.

\section{DATA ANALYSIS}

MSD software and SigmaPlot version 8.0 were used for fitting ELISA calibration curves. Data were plotted by using version 2.98 of the program FigP (Biosoft). For each group of individuals or patients studied, the median, 25th percentile, 75th percentile, and interquartile range were determined. Comparisons of hepcidin-25 concentrations between respective groups were performed by using the Wilcoxon nonparametric rank sum test. In each case, a $\mathrm{P}$ value of $<0.05$ was considered to indicate statistical significance.

\section{RESULTS}

We compared sandwich ELISA hepcidin-25 results in hemodialysis patients ( $\mathrm{n}$ $=10$ ) to results of healthy individuals $(n=40)$. These comparisons (Table 1$)$ demonstrated that hepcidin-25 concentrations were increased in hemodialysis patients (median $33.05 \mu \mathrm{g} / \mathrm{l}$, range $22.31-60.98 \mu \mathrm{g} / \mathrm{l}$ ) compared with healthy individuals (median $12.41 \mu \mathrm{g} / \mathrm{l}$, range $6.05-18.53 \mu \mathrm{g} / \mathrm{l}$ ).

The sandwich ELISA method produces a typical calibration curve for the recombinant hepcidin25-His (Fig. 1). The analytical limit of detection of the ELISA assay, defined as the concentration corresponding to the mean signal +3 SD of 10 replicates of the zero calibrator was $0.020 \mu \mathrm{g} / \mathrm{l}$. The measurement range was 0.0625 $-8 \mu \mathrm{g} / \mathrm{l}$. For the statistical analysis of the reproducibility, linearity and recovery of the hepcidin ELISA assay, we used 3 serum samples ranging from low $(21.15 \mu \mathrm{g} / \mathrm{l})$ to high $(214.84 \mu \mathrm{g} / \mathrm{l})$ concentrations chosen from 40 normal sera tested. The intraassay coefficients of variance (CVs) were $1.69-4 \%$ as evaluated by assaying 12 replicates of each sample in a single assay (Table 2). The inter-assay CVs were $0.89-4.54 \%$ as evaluated by 5 subsequent measurements of the test samples (Table 3). Intra- and inter-assay CV for the standard curve were $0.65 \%$ and $7.82 \%$, respectively. Analytical recovery was studied by adding the calibrator at 8 and $2 \mu \mathrm{g} / \mathrm{l}$ in 
each serum sample and was found to range from $96 \%-109 \%$ with a mean recovery index of $103 \%$ (Table 4 ).

Table 1. Comparison of serum hepcidin-25, serum iron, TSAT, hemoglobin and RBC in healthy individuals with the concentrations in hemodialysis patients

\begin{tabular}{|c|c|c|c|}
\hline & & Control & $\mathrm{HdP}$ \\
\hline \multirow{3}{*}{ serum Hepcidin } & $\min$ & 6.05 & 22.31 \\
\hline & $\max$ & 18.53 & 60.98 \\
\hline & aver & 12.41 & 33.05 \\
\hline \multirow{3}{*}{ serum Iron } & $\min$ & 10.60 & 5.60 \\
\hline & $\max$ & 39.00 & 34.10 \\
\hline & aver & 19.14 & 13.42 \\
\hline \multirow{3}{*}{ TSAT } & $\min$ & 17.19 & 10.41 \\
\hline & $\max$ & 63.93 & 61.13 \\
\hline & aver & 30.90 & 30.42 \\
\hline \multirow{3}{*}{ Hemoglobin } & $\min$ & 117.00 & 84.00 \\
\hline & $\max$ & 172.00 & 115.00 \\
\hline & aver & 143.70 & 99.20 \\
\hline \multirow{3}{*}{ RBC } & $\min$ & 3.80 & 2.58 \\
\hline & $\max$ & 6.14 & 3.79 \\
\hline & aver & 4.96 & 3.28 \\
\hline
\end{tabular}

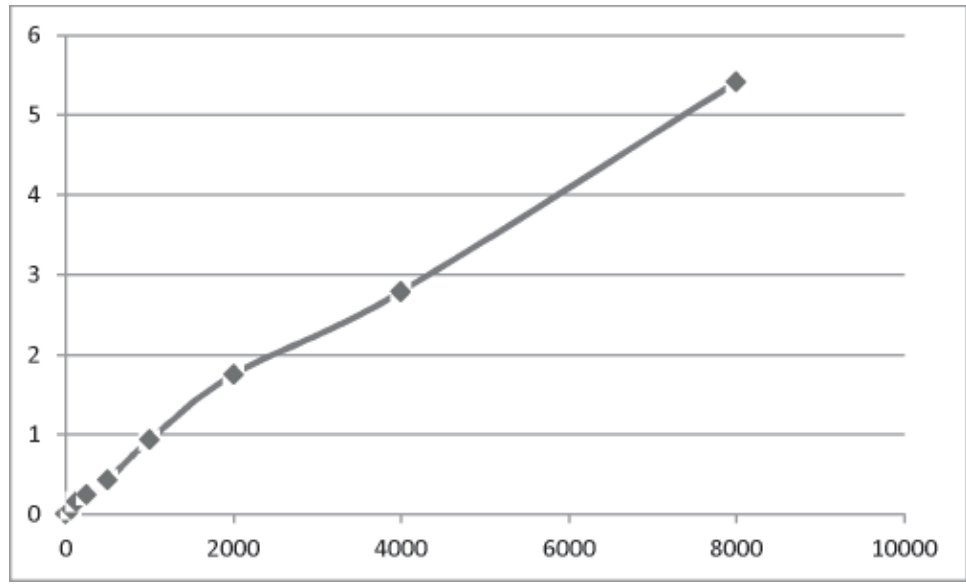

Fig. 1. Representative calibration curve for recombinant hepcidin25-His. The range of the assay is $0.0625-8 \mu \mathrm{g} / \mathrm{l}$ 
Table 2. Intra-assay variation

\begin{tabular}{|c|c|c|c|}
\hline \multirow{2}{*}{ real } & Smpl 1 & Smpl 2 & Smpl 3 \\
\hline & 21.15 & 108.92 & 214.84 \\
\hline \multirow{12}{*}{ 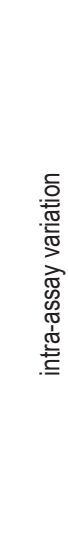 } & 20.45 & 108.84 & 210.14 \\
\hline & 21.15 & 104.55 & 209.87 \\
\hline & 20.98 & 106.98 & 215.47 \\
\hline & 21.01 & 109.84 & 216.28 \\
\hline & 22.98 & 110.01 & 211.44 \\
\hline & 21.29 & 115.52 & 204.55 \\
\hline & 20.01 & 107.51 & 213.85 \\
\hline & 20.87 & 108.14 & 214.88 \\
\hline & 21.11 & 109.51 & 217.85 \\
\hline & 19.47 & 110.84 & 215.01 \\
\hline & 21.17 & 111.1 & 212.88 \\
\hline & 21.22 & 111.14 & 211.84 \\
\hline aver & 20.98 & 109.50 & 212.84 \\
\hline SD & 0.84 & 2.71 & 3.59 \\
\hline CV & 4.00 & 2.47 & 1.69 \\
\hline
\end{tabular}

Table 3. Inter-assay variation

\begin{tabular}{|c|c|c|c|}
\hline \multirow{2}{*}{ real } & Smpl 1 & Smpl 2 & Smpl 3 \\
\hline & 21.15 & 108.92 & 214.84 \\
\hline \multirow{5}{*}{ 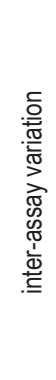 } & 21.15 & 108.92 & 214.84 \\
\hline & 20.11 & 107.01 & 215.99 \\
\hline & 19.98 & 106.99 & 211.74 \\
\hline & 22.14 & 110.52 & 214.99 \\
\hline & 21.7 & 107.85 & 216.78 \\
\hline aver & 21.02 & 108.26 & 214.87 \\
\hline SD & 0.95 & 1.49 & 1.92 \\
\hline CV & 4.54 & 1.38 & 0.89 \\
\hline
\end{tabular}

Table 4. Recovery of calibrator added to human serum samples

\begin{tabular}{|c|c|c|c|c|c|c|}
\hline real & 21.15 & & 108.92 & & 214.84 & \\
\hline \multirow{6}{*}{ 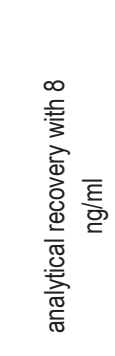 } & & $\%$ & & $\%$ & & $\%$ \\
\hline & 21.96 & 103.83 & 111.47 & 102.34 & 212.84 & 99.07 \\
\hline & 20.95 & 99.05 & 116.88 & 107.31 & 209.89 & 97.70 \\
\hline & 20.41 & 96.50 & 118.74 & 109.02 & 224.98 & 104.72 \\
\hline & 21.65 & 102.36 & 118.77 & 109.04 & 226.14 & 105.26 \\
\hline & 21.5 & 101.65 & 119.78 & 109.97 & 221.85 & 103.26 \\
\hline real & 21.15 & & 108.92 & & 214.84 & \\
\hline \multirow{6}{*}{ 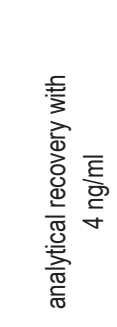 } & & $\%$ & & $\%$ & & $\%$ \\
\hline & 22.14 & 104.68 & 111.14 & 102.04 & 217.11 & 101.06 \\
\hline & 21.99 & 103.97 & 109.89 & 100.89 & 214.55 & 99.87 \\
\hline & 20.19 & 95.46 & 114.14 & 104.79 & 219.54 & 102.19 \\
\hline & 21.45 & 101.42 & 107.89 & 99.05 & 212.87 & 99.08 \\
\hline & 22.08 & 104.40 & 112.45 & 103.24 & 222.54 & 103.58 \\
\hline
\end{tabular}




\section{CLINICAL EVALUATION IN IRON DISORDERS}

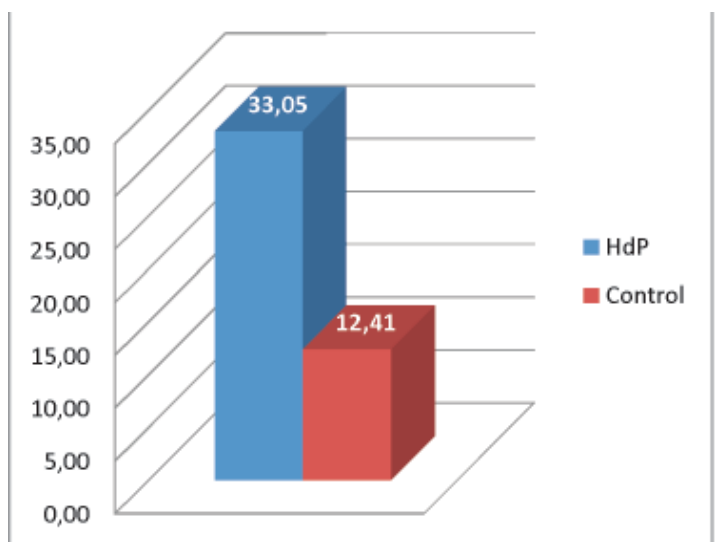

Fig. 2. Hepcidin serum concentration in healthy controls (control) and hemodialysis patients (HdP)

Significant difference compared to control is indicated by asterisk $(p<0.05)$.

Serum hepcidin levels in 40 healthy controls ranged from 6.05 to $18.53 \mu \mathrm{g} / \mathrm{l}$ (Fig. 2), and the levels correlated with serum iron levels (Pearson correlation: 0.133, $p<0.001$ ) and with TSAT (calculation based on serum iron levels and total iron binding capacity) (Pearson correlation: 0.206, p < 0.001) (Fig. 3).

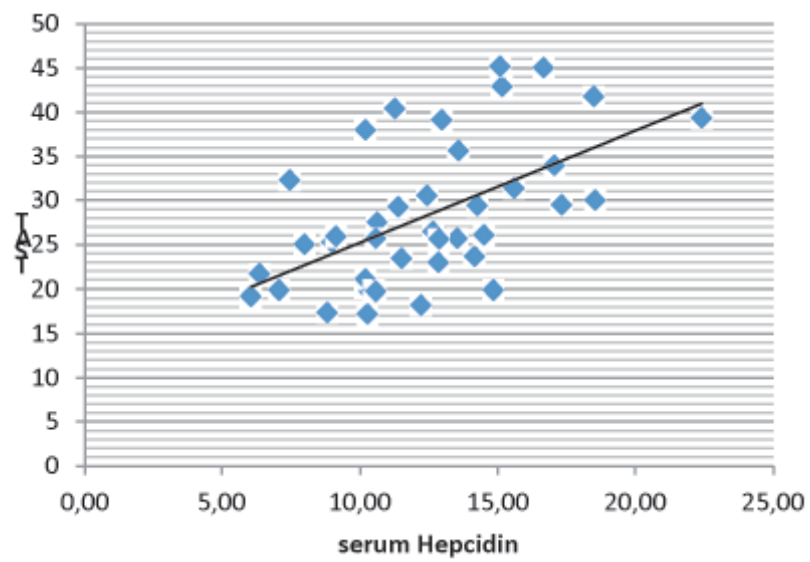

Fig. 3. Correlation between serum hepcidin and TSAT in healthy controls $(r=0.32)$

\section{DISCUSSION}

The present study describes an immunological assay for hepcidin quantification in human serum, based on the use of a recombinant hepcidin peptide and a polyclonal antibody. 
After examining the analytical characteristics of this assay, which were found satisfactory, we proceeded in determining the clinical value of it by measuring hepcidin levels in patients with iron disorders in chronic kidney diseases (in particular hemodialysis). We found significantly higher hepcidin levels in hemodialysis patients, as expected. These results allow us to conclude that this ELISA system can effectively quantify hepcidin in human serum.

Our results demonstrate that the sandwich ELISA is capable of measuring hepcidin-25 concentrations in human serum.

Compared with existing assays that use a competitive format (either ELISA or RIA), this method has advantages inherent in the sandwich assay format. In particular, responses are directly correlated with increasing hepcidin concentrations. In contrast, in competitive ELISA methods, absorbance values are inversely correlated with hepcidin concentrations $[2,3,5,10,13]$. Another advantage of this assay is its improved limit of quantification of $0.020 \mu \mathrm{g} / \mathrm{l}$ compared with existing assays.

In patients with anemia of chronic disease that is unresponsive to erythropoietin, this hepcidin ELISA may be used to verify that increased serum hepcidin is at least partly responsible for the erythropoietin-resistant anemia. Likewise, in the setting of chronic renal disease, this ELISA could be used to determine serum hepcidin concentrations to better direct therapy.

This sandwich ELISA could also be used to help diagnose iron deficiency anemia in difficult cases in which it may coexist with anemia of chronic disease. In uncomplicated iron deficiency, hepcidin concentrations would be expected to be quite low, whereas in anemia of chronic disease without coexisting iron deficiency, hepcidin concentrations would be expected to be increased $[2,8,18,26]$. Thus, in patients with anemia of chronic disease, a relatively low serum hepcidin concentration might also indicate the presence of coexisting iron deficiency.

\section{Acknowledgments}

We kindly appreciate help of Medical University - Sofia, grant № 10/2013.

\section{REFERENCES}

1. A ndrews, N. C. Anemia of inflammation: the cytokine-hepcidin link. - J. Clin. Invest., 113, 2004, 1251-1253.

2. A n th o n y, M. et al. Dual-Monoclonal Sandwich ELISA Specific for Hepcidin-25. - Clin. Chem., 56, 2010, № 11, 1725-1732.

3. A s h by, D. R. et al. Erythropoietin administration in humans causes a marked and prolonged reduction in circulating hepcidin. - Haematologica, 95, 2010, 505-508.

4. Ash by, D. R. et al. Plasma hepcidin levels are elevated but responsive to erythropoietin therapy in renal disease. - Kidney Int., 75, 2009, 976-981.

5. B u sbridge, M. et al. Development of a novel immunoassay for the iron regulatory peptide hepcidin. - Br. J. Biomed. Sci., 66, 2009, 150-157.

6. De Domenico, I. et al. The molecular mechanism of hepcidin-mediated ferroportin down-regulation. - Mol. Biol. Cell., 18, 2007, 2569-2578. 
7. Do nova n, A. et al. The iron exporter ferroportin/SIc40a1 is essential for iron homeostasis. - Cell. Metab., 1, 2005, 191-200.

8. Fle ming, R. E. et W. S. Sly. Hepcidin: a putative iron-regulatory hormone relevant to hereditary hemochromatosis and the anemia of chronic disease. - Proc. Natl. Acad. Sci. USA, 98, 2001, 8160-8162.

9. G anz, T. Hepcidin-a regulator of intestinal iron absorption and iron recycling by macrophages. Best Pract. Res. Clin. Haematol., 18, 2005, № 2, 171-182.

10. Koliaraki, V. et al. A novel immunological assay for hepcidin quantification in human serum. PLoS One, 4, 2009, e4581.

11. Krau se, A. et al. LEAP-1, a novel highly disulfide-bonded human peptide, exhibits antimicrobial activity. - FEBS Lett., 480, 2000, № 2-3, 147-150.

12. Kulaksiz, H., et al. Pro-hepcidin: expression and cell specific localisation in the liver and its regulation in hereditary haemochromatosis, chronic renal insufficiency, and renal anaemia. - Gut., 53, 2004, № 5, 735-743.

13. Lu ukk on en, S. et K. Punnonen. Serum pro-hepcidin concentrations and their responses to oral iron supplementation in healthy subjects manifest considerable inter-individual variation. - Clin. Chem. Lab. Med., 44, 2006, 1361-1362.

14. Maly szko, J. et M. Mysliwiec. Hepcidin in anemia and inflammation in chronic kidney disease. Kidney Blood Press. Res., 30, 2007, 15-30.

15. N e m e th , E. et al. (2004) IL-6 mediates hypoferremia of inflammation by inducing the synthesis of the iron regulatory hormone hepcidin. - J. Clin. Invest., 113, 2004, № 9, 1271-1276.

16. Ne meth, E. et al. Hepcidin regulates cellular iron efflux by binding to ferroportin and inducing its internalization. - Science, 306, 2004, № 5704, 2090-2093.

17. P a rk, C. H. et al. Hepcidin, a urinary antimicrobial peptide synthesized in the liver. - J. Biol. Chem., 276, 2001, № 11, 7806-7810.

18. P ig e o n, C. et al. A new mouse liver-specific gene, encoding a protein homologous to human antimicrobial peptide hepcidin, is overexpressed during iron overload. - J. Biol. Chem., 276, 2001, 7811-7819.

19. Rivera, S. et al. Hepcidin excess induces the sequestration of iron and exacerbates tumor-associated anemia. - Blood, 105, 2005, 1797-802.

20. Ro etto, A. et al. Mutant antimicrobial peptide hepcidin is associated with severe juvenile hemochromatosis. - Nat. Genet., 33, 2003, 21-22.

21. Ta e s, Y. E. et al. (2004) Prohepcidin accumulates in renal insufficiency. - Clin. Chem. Lab. Med., 42, 2004, № 4, 387-389.

22. Th e u rl, I. et al. Dysregulated monocyte iron homeostasis and erythropoietin formation in patients with anemia of chronic disease. - Blood, 107, 2006, 4142-4148.

23. Valore, E. V. et T. Ganz. Posttranslational processing of hepcidin in human hepatocytes is mediated by the prohormone convertase furin. - Blood Cells Mol. Dis., 40, 2008, № 1, 132-138.

24. Van der Putten, K. et al. Mechanisms of disease: erythropoietin resistance in patients with both heart and kidney failure. - Nat. Clin. Pract. Nephrol., 4, 2008, 47-57.

25. Kolia ra ki, V. et al. A Novel Immunological Assay for Hepcidin Quantification in Human Serum. PloS one, 4, 2009, № 2, e4581.

26. We instein, D. A. et al. Inappropriate expression of hepcidin is associated with iron refractory anemia: implications for the anemia of chronic disease. - Blood, 100, 2002, 3776-3781.

\author{
Corresponding author: \\ V. Manolov \\ Department of Clinical Laboratory and Clinical Immunology \\ Medical Faculty, Medical University \\ 1 Sv. Georgy Sofiyski st. \\ $\mathrm{Bg}-1431$ Sofia
}

